\title{
Psychology
}

OF SPORT AND EXERCISE

Psychology of Sport and Exercise 3 (2002) 261-272

www.elsevier.com/locate/psychsport

\section{The influence of crowd noise and experience upon refereeing decisions in football}

\author{
A.M. Nevill ${ }^{\mathrm{a}, *}$, N.J. Balmer ${ }^{\mathrm{b}}$, A. Mark Williams ${ }^{\mathrm{b}}$

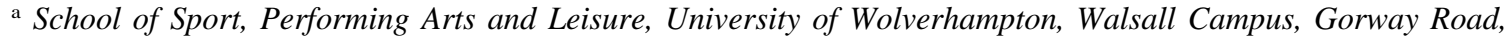 \\ Walsall WS1 3BD, UK \\ ${ }^{\mathrm{b}}$ Research Institute for Sport and Exercise Sciences, Liverpool John Moores University, Trueman Building, \\ Webster Street, Liverpool L3 2ET, UK
}

Received 21 November 2000; received in revised form 24 April 2001; accepted 12 September 2001

\begin{abstract}
Objective. The existence of the home advantage in sport is well known. There is growing evidence that crowd noise plays a crucial part in this phenomenon. Consequently, a quantitative study was undertaken to examine influence of crowd noise upon refereeing decisions in association football (soccer). The association between years of experience and any imbalance in refereeing decisions was also addressed.

Methods. To investigate whether the presence or absence of crowd noise might influence qualified referees when assessing various tackles/challenges recorded on videotape. Binary logistic regression was used to assess the effect of crowd noise and years of experience on referees' decisions.

Results. The presence of crowd noise had a dramatic effect on the decisions made by referees. Those viewing the challenges with background crowd noise were more uncertain in their decision making and awarded significantly fewer fouls (15.5\%) against the home team, compared with those watching in silence.

Conclusions. The noise of the crowd influenced referees' decisions to favour the home team. It is suggested that referees' decisions are influenced by the salient nature of crowd noise, the potential use of heuristic strategies, and the need to avoid potential crowd displeasure by making a decision in favour of the home team. (C) 2002 Elsevier Science Ltd. All rights reserved.
\end{abstract}

Keywords: Referees; Decision making; Home advantage

* Corresponding author. Tel.: +44-1902-322898; fax: +44-1902-322894.

E-mail address: a.m.nevill@wlv.ac.uk (A.M. Nevill). 


\section{Introduction}

In their influential review, Courneya and Carron (1992, p. 13) defined the home advantage in team games as "the consistent finding that home teams in sports competitions win over $50 \%$ of the games played under a balanced home and away schedule". Evidence supporting such an advantage in team sports is now overwhelming (Agnew \& Carron, 1994; Courneya \& Carron, 1992; Nevill, Newell, \& Gale, 1996; Pollard, 1986; Schwartz \& Barsky, 1977; Snyder \& Purdy, 1985; Varca, 1980). For example, in basketball, based on 13,686 matches, the home winning percentage was $64.4 \%$ (Nevill \& Holder, 1999). Similar values have been observed for association football (soccer, hereafter referred to as 'football'), with a home winning percentage of $68.3 \%$ (excluding draws) over some 40,493 matches (Nevill \& Holder, 1999). Further examples are provided in Table 1, confirming that the home advantage is a crucial factor influencing success in major team sports.

Courneya and Carron (1992) argued that further verification of the existence of the home advantage (i.e. the 'what' of the home advantage) is no longer a sufficient rationale to justify game location research. They recommended that future research explore the reasons 'when' and 'why' the home advantage occurs. In their seminal review, Courneya and Carron (1992) identified the following four game location factors as likely to cause or effect the degree of the home advantage: (1) crowd factors; (2) learning/familiarity factors; (3) travel factors; (4) rule factors. Based on the latest evidence, Nevill and Holder (1999, p. 221) concluded that, "crowd factors appeared to be the most dominant cause of the home advantage".

Schwartz and Barsky (1977) found that the home advantage in Major League baseball increased with crowd density. The trend in the home advantage increased from $48 \%$ in relatively empty stadia (less than $20 \%$ capacity), to $55 \%$ when the stadia were between 20 and $40 \%$ capacity and to $57 \%$ when crowd density was greater than $40 \%$ capacity. Similarly, using multiple regression, Agnew and Carron (1994) showed crowd density to be significantly related to the home advantage in major junior-A ice hockey $\left(R^{2}=0.011, p<0.001\right)$.

The depleted home advantage in matches involving English football's 13 London clubs (Clarke \& Norman, 1995), and in local derbies in general (Pollard, 1986), provides further support of a possible crowd influence. Local matches generally attract an increased number of away supporters, given the decreased distances involved. Similarly, given their number, the London

Table 1

The combined home winning percentages (weighted) for the major team sports (source: Nevill and Holder (1999). Reproduced by kind permission of Adis Publishers)

\begin{tabular}{llcll}
\hline Sport & Total studies & Total games & HWP $^{\mathrm{a}}$ & HWP $^{\mathrm{b}}$ \\
\hline Baseball & 1 & 133,560 & - & 54.3 \\
American football & 5 & 2592 & 57.3 & 57.3 \\
Ice hockey & 5 & 5312 & 59.5 & 61.2 \\
Basketball & 9 & 13,686 & - & 64.4 \\
Soccer & 3 & 40,493 & 63.9 & 68.3 \\
\hline
\end{tabular}

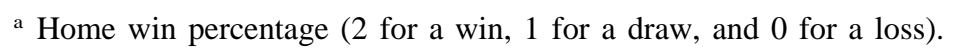

b Home win percentage (drawn games excluded). 
clubs play a far greater number of derbies, possibly accounting for the discrepancy observed by Clarke and Norman (1995).

Nevill et al. (1996) also observed a significant home advantage in football that appeared to increase in divisions with larger crowds. However, the greatest home advantage in percentages of wins, away players being sent off, and home penalties scored, was not in the English Premier League but in the English First Division where crowd sizes were considerably less. These results suggest that once the crowd has reached a certain size or density, a peak in the home advantage is observed. These studies provide some evidence that the size and consistency of the crowd can influence the degree of the home advantage. This finding led to the suggestion that the crowd is able to either raise the performance of home competitors, or subconsciously influence the officials to favour the home team (Nevill \& Holder, 1999).

Support for the latter of these hypotheses comes from studies that report officials consistently making more subjective decisions in favour of the home team (Glamser, 1990; Greer, 1983; Lefebvre \& Passer, 1974; Lehman \& Reifman, 1987; Sumner \& Mobley, 1981; Varca, 1980). Moreover, Nevill et al. (1996) confirmed that not only do officials in English and Scottish football make more subjective decisions in favour of the home team (penalties and sendings-off), but also the observed imbalance appears to increase in divisions with larger crowds.

Lehman and Reifman (1987) examined the association between player status (star vs. non-star) and the number of fouls called against professional basketball players both home and away. The results found that star players were penalised significantly less when playing at home rather than away. In contrast, no differences were found for non-star players. Lehman and Reifman (1987, p. 674) concluded that "this pattern may reflect officials' reacting to pressure from the home crowd", a conclusion not dissimilar to that of Glamser (1990, p. 48) who suggested that "the hostile atmosphere of an away game where such (social) support is lacking can clearly produce a dysfunctional aggressive response on the part of the visiting player and a less-than-objective view on the part of officials".

Studies by Thirer and Rampey (1979) and Greer (1983) also recognised the influence that crowds might have on the home advantage. In college basketball, Thirer and Rampey (1979) found that during normal crowd behaviour the visiting teams committed more infractions (i.e. committed more fouls and lost more possessions or turnovers). During antisocial crowd behaviour (swearing, chanting obscenities), however, home teams committed more infractions. The authors conclude that "anti-social behaviour from the crowd had a detrimental effect on the home team" (p. 1047).

Greer (1983) assessed the effect of crowd behaviour (spectator booing) on home and away teams' performance outcomes (points scored, turnovers, violations and composite score comprising points scored minus turnovers and violations). Greer observed that during normal crowd behaviour, home teams were better on all four performance measures. During those instances when the crowd was booing (for longer than $15 \mathrm{~s}$ ), the home teams' superiority increased further, two of the four performance measures being significant. Greer speculated that the observed increase in the home teams' performance (home advantage) was due to either a decrement in the visiting teams' performance or to referee bias resulting from intimidation by the home crowd (since most of the booing was directed at the officials). Interestingly, the two studies disagreed regarding the influence of antisocial crowd behaviour. This could reflect difficulty in differentiating systematic officiating error from improvements or deteriorations in player performance. 
Both studies used quasi-experimental designs to identify the effect of various aspects of crowd behaviour (cheering, booing), and the degree (intensity), on performance outcomes (e.g. fouls). However, by adopting such designs, researchers recognise that it is almost impossible to untangle other associations that might confound the observed performance outcomes. For example, differences in the number of observed fouls in favour of the home team could be due to a number of other home advantage factors, such as frustration or aggression on the part of the away team, or the use of more defensive tactics by the away team.

Research focusing specifically upon officiating has consistently shown that errors and bias are inevitable due to limitations in perceptual function (Sanabria et al., 1998). For example, Larsen and Rainey (1991) applied Wundt's theory of prior entry (that auditory stimuli appear to occur prior to the time of actual occurrence) to demonstrate bias in baseball's first base calls. Subsequently, using a computer simulation of the leg before wicket decision in cricket, Craven (1998) identified changing bias as a result of varying swing, point of release and side of the wicket toward which deliveries were aimed.

In football, Sanabria et al. (1998) calculated theoretical inaccuracies associated with four simple offside decisions. They suggested that latency and duration of saccadic eye movements lead to an erroneous image of player positions, resulting in bias. Oudejans et al. (2000) expanded upon this experimentally, placing head-mounted cameras on assistant referees. In addition to the specific bias detected in conjunction with relative positions of attacker and defender, $9.3 \%$ of trials was found to be 'Flag Errors', that might be termed 'false alarms' had signal detection methodology been employed. Other instances have shown general bias as a result of pitcher reputation in baseball (Rainey, Larsen, \& Stephenson, 1989), nationalistic and political bias in Olympic skating (Seltzer \& Glass, 1991; Whissell, Lyons, Wilkinson, \& Whissell, 1993) and gymnastics (Ansorge \& Scheer, 1988), as well bias in the home advantage in conjunction with subjective officiating (Balmer, Nevill, \& Williams, 2001).

Two sources of systematic error have been identified which would suggest the crowd would have an influence upon officiating (see Wickens \& Hollands, 2000). Wallsten and Barton (1982) showed that when participants are placed under time constraints they are likely to focus on the most salient cues. These tend to be cues that attract the greatest attention or those that are easier to process regardless of their diagnostic value (Payne, 1980). A suggestion is that when faced with a contentious decision, the effects of crowd noise will be particularly salient for referees by guiding or constraining their search towards cues that favour the home team. This is confirmed by research suggesting that information that is difficult to interpret will be under processed or ignored (Bettman, Johnson, \& Payne, 1990; Johnson, Payne, \& Bettman, 1988; Stone, Yates, \& Parker, 1997). Since crowd noise lacks reliability and is not diagnostic in nature, this would result in more decisions in favour of the home side.

Similarly, research involving the use of heuristics in decision making suggests that crowd noise should be influential. Heuristics are rules of thumb used to reduce complex judgements to more simple ones, though they frequently result in systematic errors (Tversky \& Kahneman, 1974). Specifically, the 'as if' heuristic suggests that if cues are not perfectly reliable or diagnostic, such cues will be utilised 'as if' they are of equal importance (Wickens \& Hollands, 2000). This leads to the extraction of more information than is warranted from an unreliable or uninformative cue (Johnson, Cavenaugh, Spooner, \& Samert, 1973; Schum, 1975). With regard to a potential bias in decision making, the referee may place equal importance on the auditory information from the 
crowd as much as that presented visually within the display leading to an imbalance of decisions in favour of the home side.

In the case of the as if heuristic, trained nurses (experts) are equally susceptible to errors in processing as novices (Rossi \& Madden, 1979), while participants trained in statistical theory are unable to apply this expertise to overcome similar predictive errors (Kahneman \& Tversky, 1973). However, this does not imply that experts would make errors of a similar magnitude to novices. Previous research suggests that experience can help alleviate the potentially negative effects of stress on performance (see Janelle, Singer, \& Williams, 1999; Williams \& Elliott, 1999). Experienced referees are likely to have greater control over their emotional states (see Hardy, Jones, \& Gould, 1996) and more enhanced task specific knowledge bases that facilitate skilled decision making in stressful environments (Williams, Davids, \& Williams, 1999).

The present study assessed whether decisions by qualified referees could be influenced by the noise of a partisan crowd. The association between years of experience and any imbalance in refereeing decisions is also determined. It is proposed that crowd noise results in fewer fouls against home players and more fouls against away players. Moreover, it is hypothesised that increasingly experienced referees are less susceptible to the influence of crowd noise, compared to their less experienced counterparts.

\section{Method}

\section{Participants}

Forty qualified referees from the North Staffordshire Referees Club in England volunteered to take part in the present study with experience ranging from newly qualified referees to 43 years of refereeing experience. The referees were asked to assess the legality of 47 challenges/incidents recorded during an English Premier League match between Liverpool (home) and Leicester City (away) from the 1998/1999 season. Participants gave their informed consent prior to take part in the study.

\section{Test film and apparatus}

The incidents were projected in chronological order, interspersed with sequences of action, onto a $1.24 \mathrm{~m} \times 1.24 \mathrm{~m}$ screen (Bell and Howard) using video-projection system (Panasonic PT-L595E) and videocassette recorder (Panasonic NV-HD680). The videotape was edited such that the presentation stopped for six seconds immediately after each incident, but fractionally before the match official's decision could be observed. The videotape comprised 47 incidents $(M=8.93 \mathrm{~s}, \mathrm{SD}=2.17$ (excluding $6 \mathrm{~s}$ pause)), with a further 13 action sequences $(M=17.21 \mathrm{~s}, \mathrm{SD}=5.08)$. Noise level was measured using a digital sound level meter (Tenma 72-680), with a $1 \mathrm{kHz}$ test tone yielding $75 \mathrm{~dB}$ (absolute) at $1 \mathrm{~m}$.

\section{Procedure}

The referees were randomly allocated to a noise group featuring crowd noise but no commentary, or a silent condition group. Twenty-two of the referees observed the video with the crowd 
noise audible (the noise condition group), whilst 18 referees viewed the video in silence. Preceding presentation, participants were informed as to the identity and strip colour of the home and away teams. Throughout the six-second pause, the corresponding incident number appeared on the screen during which time participants were invited to record their adjudications on a response sheet. Participants were asked to give their opinion on whether the 47 challenges were either legal (no foul) or illegal (a foul). If the challenge was deemed illegal, the referees were asked to indicate whether it was a home (home foul) or an away player (away foul) who had committed the foul. A fourth 'uncertain' option was also available on the response sheet, although it was recognised that in a 'live' game situation, if uncertain, the referee would have chosen the "no foul' option. Consequently, in response to each challenge, the referees were asked to choose one of four possible options, either (1) home foul, (2) away foul, (3) no foul or (4) uncertain.

\section{Analysis}

Because the response variable was categorical (home foul vs. away foul vs. no foul vs. uncertain), the assumptions necessary to conduct hypothesis tests using ANOVA are likely to be violated. A more appropriate technique to analyse categorical data is logistic regression. The analysis will estimate the probabilities (or more correctly the odds) associated with the four categorical options and how these probabilities will vary due to differences in the predictor/independent variables (see Kleinbaun, 1994). Note that in order to describe the strength of an effect (equivalent to an effect size in traditional ANOVA), logistic regression calculates the odds ratio, that is the ratio of the odds of, for example, penalising the home players under silent condition, compared with (divided by) the odds of penalising the home player under the noise condition.

As described above, when viewing the 47 challenges, referees were asked to choose one of four options. Hence, for each of the 40 referees, the 47 decisions were collapsed into one of these four options. For example, referee number 1 chose 12 'home fouls', 6 'away fouls', 14 'no fouls' and 15 'uncertain' (note that the sum of the responses to the 4 options will always total 47). Binary logistic regression was used to assess the effect of the independent variables, crowd noise and years of experience, on each outcome variable/option separately. For example, when analysing the home foul option, binary logistic regression estimates the probability of awarding a home foul $(p)$ vs. not awarding a home foul $(1-p)$ and how this probability will vary due to the differences in, or the effects of, the independent variables. For the purpose of the present analysis, 'years of experience' was entered as a continuous variable with both linear and quadratic terms. This would enable the analysis to identify non-linear trends in the referees' responses with years of experience. The statistical software Generalised Linear Interactive Modelling (GLIM; Atkin, Anderson, Francis, \& Hinde, 1989) was used to analyse the binomial response variables. The method of model simplification adopted was backward elimination (see Draper \& Smith, 1981), in which at each step the least important variable was dropped from the current model. Importance was assessed by the 'change in deviance' $\left(\chi^{2}\right)$ that resulted from dropping the variable in question from the current model. All error bars on figures denote standard errors of means. 


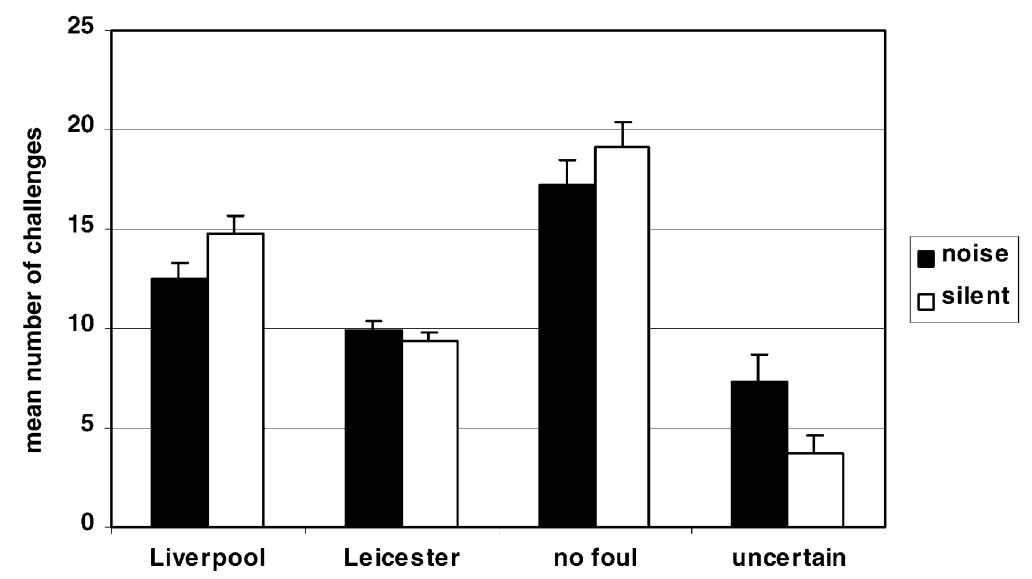

Fig. 1. Mean number of challenges for each of the four response options awarded by the noise and silent condition groups.

\section{Results}

Fig. 1 illustrates the mean number of challenges for each option awarded by the noise and silent condition groups. In comparison with the noise group, the silent condition participants were more certain with their decisions (fewer uncertain responses), awarded a greater number of fouls against home players, and chose more no foul options.

To compare the responses of the referees with those of the match referee, the no foul and uncertain options were collapsed into a single no foul option. The mean number of challenges for the three remaining options (home foul, away foul, and no foul) awarded by the two groups of referees and the match referee is illustrated in Fig. 2. Interestingly, the responses made by the referees in the noise condition group agree very closely with those of the match referee. Differ-

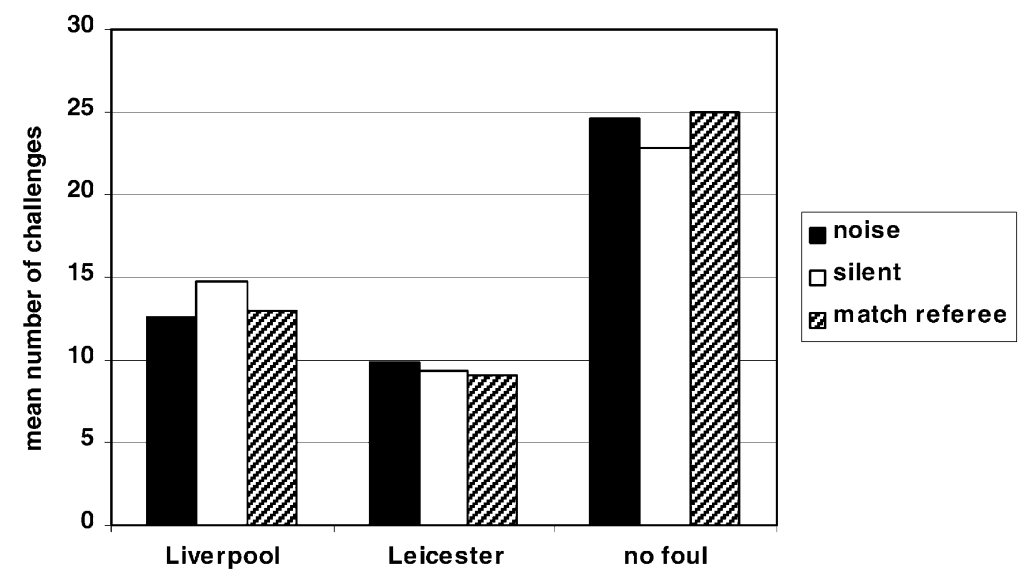

Fig. 2. Mean number of challenges for the remaining three response options awarded by the noise condition group, silent condition group and match referee, (no foul and uncertain options collapsed into a single no foul option). 
ences were investigated separately for each option (home foul, away foul, no foul and uncertain) using binary logistic regression.

\section{Binary logistic regression analyses}

For home fouls, binary logistic regression analysis identified a significant effect due to "crowd noise'. Removing the noise group factor from the final model resulted in a significantly large change in deviance $\left(\chi^{2}(1)=3.875\right.$; odds ratio, $\left.\exp (\beta)=1.22, p<0.05\right)$. The group of referees watching the video with the crowd noise audible awarded significantly less fouls $(15.5 \%)$ against the home players $(M=12.5)$ compared with referees in the silent group $(M=14.8)$ (see Fig. 1).

Binary regression also identified a significant non-linear effect of years of experience on the number of home fouls awarded by the referees. Again backward elimination of both linear $\left(\chi^{2}(1)=4.443, p<0.05\right)$ and quadratic $\left(\chi^{2}(1)=6.059, p<0.05\right)$ years of experience terms resulted in large changes in deviance. The positive linear $(0.031)$ and negative quadratic term $(-0.00096)$ identified in the analysis suggest that the number of home fouls increased with years of experience until a peak at 16 years of refereeing experience (using elementary differential calculus), thereafter a decline in home fouls was observed. Importantly, introduction of experience by noise group interaction terms yielded insignificant changes in deviance, suggesting that the influence of crowd noise on home fouls is not dependent upon refereeing experience.

When the away fouls were analysed, the linear and quadratic years of experience and crowd noise had no significant effect on the referees' decisions. Removing the crowd noise factor resulted in small change in deviance $\left(\chi^{2}(1)=0.265, p>0.05\right)$. For the no foul option, removal of crowd noise resulted in a large change in deviance $\left(\chi^{2}(1)=3.652\right)$; odds ratio, $\left.\exp (\beta)=1.19, p=0.056\right)$, with the noise condition group of referees awarding an average of 17.2 no fouls compared with 19.2 no fouls awarded by the silent condition group. There was also a significant 'years of experience' effect (linear term only) $\left(\chi^{2}(1)=6.578, p<0.05\right)$. The linear trend of years of experience reflected a significant reduction in no fouls by the most experienced referees. As with the home foul option, introduction of experience by noise group interaction terms had little influence.

Analysis of the uncertain option was similar to the no foul decisions. Again, removal of crowd noise resulted in highly significant changes in deviance $\left(\chi^{2}(1)=25.97\right.$; odds ratio, $\exp (\beta)=0.47$, $p<0.001$ ), as did years of experience (linear term only) $\left(\chi^{2}(1)=13.13, p<0.001\right)$. The positive linear regression term of years of experience suggests that the most experienced referees were more uncertain when making their decisions. However, most importantly, there was an increase in the number of uncertain decisions by referees in the noise $(M=7.4)$ compared with the silent $(M=3.7)$ condition group (see Fig. 1). As with both home foul and no foul analyses, introduction of experience by noise group interactions led to insignificant changes in deviance.

\section{Discussion}

The present study had two objectives. First, the study examined whether the decisions made by qualified football referees' could be influenced by the noise of a partisan crowd. Second, an attempt was made to determine the association of refereeing experience with any imbalance of decisions. It was hypothesised that crowd noise would result in greater leniency toward the home, 
and greater severity toward the away team. Increasing experience was expected to diminish this imbalance.

The presence or absence of crowd noise did have a dramatic effect on the decisions made by the qualified referees. The bias observed was in agreement with the hypothesis that the crowd is able to influence officiating (Nevill \& Holder, 1999; Nevill, Balmer, \& Williams, 1999). Those referees viewing challenges in the noise condition were more uncertain when making their decisions, and awarded significantly fewer fouls $(15.5 \%)$ against the home team $(M=12.5)$ than the silent group $(M=14.8)$. Although in absolute terms, 2.3 fewer home fouls (noise group) out of a total 14.8 (silent group) does not appear to be large, in percentage terms $(15.5 \%)$, it reflects approximately the same percentage difference/advantage reported for home wins in soccer (see Table 1, i.e. $63.9 \%$ including draws or $68.3 \%$ excluding draws). Although the noise group did penalise the away team more often ( $M=9.9$ fouls) than the silent group ( $M=9.3$ fouls), this difference was marginal and not significant.

Interestingly, the present study indicated that the dominant effect of crowd noise was to significantly reduce the number of fouls awarded against the home team, rather than increase the number of fouls against the away team. This finding seems reasonable given previous research in basketball which showed that fewer fouls were given against 'star' players at home, though this was not the case with 'non-stars' (Lehman \& Reifman, 1987). The present findings, therefore, could be partially a result of such a star player effect. The noise group's decisions also mirrored very closely those of the match referee (see Fig. 2), providing strong 'external validity' for the experiment. Presumably, the partisan crowd was able to influence the referees in the noise condition group in a similar way to the match referee.

Years of experience had a significant effect on the number of fouls awarded by the referees against the home players, increasing with years of experience until a peak at approximately 16 years, thereafter a decline was observed. The other major effect of refereeing experience was to significantly increase the number of uncertain decisions by the most experienced/older referees. Despite these differences, the lack of an interaction between 'refereeing experience' and 'crowd noise' suggests that these observed changes with refereeing experience were consistent between noise conditions. Evidently, here as in previous research (Craven, 1998; Larsen \& Rainey, 1991; Oudejans et al., 2000; Rainey et al., 1989; Rainey, Larsen, \& Willard, 1987; Sanabria et al., 1998), officiating errors are inevitable. Such errors were confirmed in the present study by the substantial disagreement and variation in the referees' decisions. Indeed, none of the 47 challenges resulted in a unanimous decision by all 40 qualified referees. Clearly, with such evidence of conflicting opinions amongst qualified referees, some of the referees must be making mistakes/errors on a regular basis. More concerning however, is the significant imbalance in decisions observed with crowd noise, particularly if governing bodies such as Fédération Internationale de Football Association (FIFA) consider employing video replay to aid on-pitch officials. Is more than one official necessary to help adjudicate such contentious replays and, most importantly, should the officials judge from a soundproof booth, avoiding the influence of crowd noise?

A number of articles have provided anecdotal evidence to suggest that referees decisions can be influenced by the crowds' reactions to favour the home team. For example, Askins (1978, p. 18) stated that "during the course of any contest there are many incidents which appear ambiguous, even to the most veteran officials. When this occurs, officials do basically what all humans do 
in such a situation, they seek clarification through any means available at the time. Crowd reaction may sometimes provide the cue which prompts the decision".

The imbalance observed between noise conditions for the home fouls is consistent with that predicted by both cue salience and use of heuristics. It would appear that in the noise condition referees rely on the salient yet potentially biased judgement of the crowd (see Wallsten \& Barton, 1982). Alternatively, they may apply an 'as if' heuristic, with the information from the crowd assuming equal or greater weight than that presented visually (see Rossi \& Madden, 1979). The significant imbalance observed with crowd noise may be a reflection of the inevitable error resulting from the use of such heuristics to integrate information (Tversky \& Kahneman, 1974).

Additionally, the findings seem entirely plausible based on work investigating officials' coping strategies in response to stressful events (Anshel \& Weinberg, 1999; Kaissidis-Rodafinos, Anshel, \& Porter, 1997). 'Making a bad call' is the single most important stressor amongst officials in volleyball (Stewart \& Ellery, 1998), a finding echoed in basketball (Kaissidis \& Anshel, 1993), and football (Taylor, Daniel, Leith, \& Burke, 1990). Given that making a bad call and crowd noise will raise levels of stress in the noise group referees in a similar way to that of the match referee (sources of stress felt to be difficult to control), the coping strategy is likely to be one of avoidance. As the crowd is likely to make it clear if they feel a decision was 'wrong', avoidance could be interpreted as simply not making the unpopular decision to penalise the home team when assessing less clear or contentious challenges. Whenever a home player commits a foul, the crowd's reaction is capable of activating the potent stressor of making a bad call, thus increasing the level of uncertainty or indecision among referees, resulting in no decision (avoidance) and fewer fouls against the home team.

The results from the present study suggest how crowd noise may affect referees' decisions. Rather than penalising the away players more, the dominant effect of crowd noise would appear to influence qualified referees to penalise the home players less. It seems plausible that this imbalance may be a result of over processing salient though undiagnostic crowd noise. This attention to the partisan home crowd results in significantly fewer decisions against the home team. Additionally, the noise condition participants may be adopting the coping strategy of 'avoidance' in an attempt to reduce the stress of making a bad call. In this case, avoidance by the referee could be interpreted as simply not making the unpopular decision to penalise the home player, thus creating the observed bias in favour of the home team. Future research could test the validity of this mechanism through the measurement and/or manipulation of stress during experimentation.

\section{Acknowledgements}

We thank David Davies and his colleagues at the North Staffordshire Referees' Club (UK) for their co-operation and help in setting up the project.

\section{References}

Agnew, G. A., \& Carron, A. V. (1994). Crowd effects and the home advantage. International Journal of Sport Psychology, 25, 53-62. 
Atkin, M., Anderson, D., Francis, B., \& Hinde, J. (1989). Statistical modelling in GLIM. Oxford: Clarendon Press.

Anshel, M. H., \& Weinberg, R. S. (1999). Re-examining coping among basketball referees following stressful events: Implications for coping interventions. Journal of Sport Behavior, 22, 141-161.

Ansorge, C. J., \& Scheer, J. K. (1988). International bias detected in judging gymnastic competition at the 1984 Olympic games. Research Quarterly for Exercise and Sport, 59, 103-107.

Askins, R. L. (1978). Observations: The official reacting to pressure. Referee, 4, 17-20.

Balmer, N. J., Nevill, A. M., \& Williams, A. M. (2001). Home advantage in the Winter Olympics (1908-1998). Journal of Sports Sciences, 19, 129-139.

Bettman, J. R., Johnson, E. J., \& Payne, J. (1990). A componential analysis of cognitive effort and choice. Organizational Behavior and Human Performance, 45, 111-139.

Clarke, S. R., \& Norman, J. M. (1995). Home ground advantage of individual clubs in English soccer. The Statistician, 44, 509-521.

Craven, B. J. (1998). A psychophysical study of leg-before-wicket judgements in cricket. British Journal of Psychology, $89,555-578$.

Courneya, K. S., \& Carron, A. V. (1992). The home advantage in sport competitions: A literature review. Journal of Sport and Exercise Psychology, 14, 13-27.

Draper, N. R., \& Smith, H. (1981). Applied regression analysis (2nd ed.). New York: Wiley.

Glamser, F. D. (1990). Contest location, player misconduct, and race: A case from English soccer. Journal of Sport Behavior, 13, 41-49.

Greer, D. L. (1983). Spectator booing and the home advantage: A study of social influence in the basketball arena. Social Psychology Quarterly, 46, 252-261.

Hardy, L., Jones, J. G., \& Gould, D. (1996). Understanding psychological preparation for sport: Theory and practice of elite performers. Chichester, UK: Wiley.

Janelle, C. M., Singer, R. N., \& Williams, A. M. (1999). External distraction and attentional narrowing: Visual search evidence. Journal of Sport and Exercise Psychology, 21, 70-91.

Johnson, E. J., Payne, J. W., \& Bettman, J. R. (1988). Information displays and preference reversals. Organizational Behavior and Human Decision Processes, 42, 1-21.

Johnson, E. M., Cavenaugh, R. C., Spooner, R. L., \& Samert, M. G. (1973). Utilization of reliability estimates in Bayesian inference. IEEE Transactions on Reliability, 22, 176-183.

Kahneman, D., \& Tversky, A. (1973). On the psychology of prediction. Psychological Review, 80, 251-273.

Kaissidis, A. N., \& Anshel, M. H. (1993). Sources and intensity of acute stress in adolescent and adult Australian basketball referees: A preliminary study. The Australian Journal of Science and Medicine in Sport, 25, 97-103.

Kaissidis-Rodafinos, A., Anshel, M. H., \& Porter, A. (1997). Personal and situational factors that predict coping strategies for acute stress among basketball referees. Journal of Sports Sciences, 15, 427-436.

Kleinbaun, D. G. (1994). Logistic regression: A self-learning text. New York: Springer.

Larsen, J. D., \& Rainey, D. W. (1991). Judgement bias in baseball umpires' first base calls: A computer simulation. Journal of Sport and Exercise Psychology, 13, 75-79.

Lefebvre, L. M., \& Passer, M. W. (1974). The effects of game location and importance on aggression in team sport. International Journal of Sport Psychology, 5, 102-110.

Lehman, D. R., \& Reifman, A. (1987). Spectator influence on basketball officiating. Journal of Social Psychology, 127, 673-675.

Nevill, A., Balmer, N., \& Williams, M. (1999). Crowd influence on decisions in association football. The Lancet, $353,1416$.

Nevill, A. M., \& Holder, R. L. (1999). Home advantage in sport: An overview of studies on the advantage of playing at home. Sports Medicine, 28, 221-236.

Nevill, A. M., Newell, S., \& Gale, S. (1996). Factors associated with home advantage in English and Scottish Soccer. Journal of Sports Sciences, 14, 181-186.

Oudejans, R. R. D., Verheijen, R., Bakker, F. C., Gerrits, J. C., Steinbrückner, M., \& Beek, P. J. (2000). Errors in judging 'offside' in football. Nature, 404, 33.

Payne, J. W. (1980). Information processing theory: Some concepts and methods applied to decision research. In T. S. Wallsten (Ed.), Cognitive processes in choice and decision behavior (pp. 95-115). Hillsdale, NJ: Erlbaum.

Pollard, R. (1986). Home advantage in soccer: A retrospective analysis. Journal of Sports Sciences, 4, 237-248. 
Rainey, D. W., Larsen, J. D., \& Stephenson, A. (1989). The effects of a pitcher's reputation on umpires' calls of balls and strikes. Journal of Sport Behavior, 12, 139-150.

Rainey, D. W., Larsen, J. D., \& Willard, M. J. (1987). A computer simulation of sport officiating behavior. Journal of Sport Behavior, 10, 183-191.

Rossi, A. L., \& Madden, J. M. (1979). Clinical judgement of nurses. Bulletin of the Psychonomic Society, 14, 281-284.

Sanabria, J., Cenjor, C., Márquez, F., Gutierrez, R., Martinez, D., \& Prados-Garcia, J. L. (1998). Oculomotor movements and football's law 11. The Lancet, 351, 268.

Schum, D. (1975). The weighing of testimony of judicial proceedings from sources having reduced credibility. Human Factors, 17, 172-203.

Schwartz, B., \& Barsky, S. F. (1977). The home advantage. Social Forces, 55, 641-661.

Seltzer, R., \& Glass, W. (1991). International politics and judging in Olympic skating events: 1968-1988. Journal of Sport Behavior, 14, 189-200.

Snyder, E. E., \& Purdy, D. A. (1985). The home advantage in collegiate basketball. Sociology of Sport Journal, 2 , 352-356.

Stewart, M. J., \& Ellery, P. J. (1998). Sources and magnitude of perceived psychological stress in high school volleyball officials. Perceptual and Motor Skills, 87, 1275-1282.

Stone, E. R., Yates, J. F., \& Parker, A. M. (1997). Effects of numerical and graphical displays on professed risk-taking behavior. Journal of Experimental Psychology: Applied, 3 (4), 243-256.

Sumner, J., \& Mobley, M. (1981). Are cricket umpires biased? New Scientist, 91, 29-31.

Taylor, A. H., Daniel, J. V., Leith, L., \& Burke, R. J. (1990). Perceived stress, psychological burnout and paths to turnover intentions among sport officials. Journal of Applied Sport Psychology, 2, 84-97.

Thirer, J., \& Rampey, M. (1979). Effects of abusive spectator behaviour on the performance of home and visiting intercollegiate basketball teams. Perceptual and Motor Skills, 48, 1047-1053.

Tversky, A., \& Kahneman, D. (1974). Judgment under uncertainty: Heuristics and biases. Science, 185, 1124-1131.

Varca, P. (1980). An analysis of home and away game performance of male college basketball teams. Journal of Sport Psychology, 2, 245-257.

Wallsten, T. S., \& Barton, C. (1982). Processing probabilistic multidimensional information for decisions. Journal of Experimental Psychology: Learning, Memory, and Cognition, 8, 361-384.

Whissell, R., Lyons, S., Wilkinson, D., \& Whissell, C. (1993). National bias in judgements of Olympic-level skating. Perceptual and Motor Skills, 77, 355-358.

Wickens, C. D., \& Hollands, J. G. (2000). Engineering psychology and human performance (3rd ed.). Upper Saddle River, NJ: Prentice Hall.

Williams, A. M., Davids, K., \& Williams, J. G. (1999). Visual perception and action in sport. London: Routledge.

Williams, A. M., \& Elliott, D. (1999). Anxiety and visual search strategy in karate. Journal of Sport and Exercise Psychology, 21, 362-375. 